fall, insolation, temperature, etc., are given for four of the islands and also for the meteorological observatories at Sidi Ifni and Cabo Jubi in Spanish West Africa. Figures and maps show the zones of totality for different places, and the four maps reproduce, on the scale of $1: 500,000$, the zones referred to in the text. This publication will be invaluable to all who contemplate observing the eclipse from the places mentioned in the text.

\section{Standard X-Ray Diffraction Powder Patterns}

THE sixth in the series of "Standard X-ray Diffraction Powder Patterns", prepared by the National Bureau of Standards, Washington, D.C., has recently been published as Circular 539 (pp. 62; 1956. 40 cents); in it are presented data for forty-four inorganic substances. Twenty-three of the patterns are to replace thirty-three already represented in the card file of the American Society of Testing Materials, and twenty-one are for compounds not previously represented. The card file serves as a system for the identification of unknown crystalline materials by matching spacing and intensity measurements. A comparison is made of all powder diffraction data available for each of the substances reported. The patterns were made with a Geiger-counter X-ray diffractometer, using samples of high purity. The $d$-values were assigned Miller indices determined by comparison with calculated interplanar spacings and from space group considerations. The densities and lattice constants were calculated, and the refractive indices were measured whenever possible. The Circular includes a cumulative index to Vols. $1-5$; but further work in the programme is in progress and the index is not therefore necessarily the concluding index in the series.

\section{British Glaciological Society}

THe following officers and Committee of the British Glaciological Society have recently been elected: President, G. Seligman; Vice-Presidents, W. V. Lewis, K. S. Sandford and Sir James Wordie; Hon. Treasurer, G. C. L. Bertram; Secretary, Mrs. H. Richardson; Committee members, R. J. Adie, P. D. Baird, J. W. Glen, S. E. Hollingworth, J. F. Nye, C. D. Ovey, B. B. Roberts, Miss M. M. Sweeting, C. W. M. Swithinbank and W. H. Ward.

\section{University College of Rhodesia and Nyasaland}

IN the article on "The University College of Rhodesia and Nyasaland" in Nature of January 19, p. 139 , it was stated that nearly half a million pounds was collected in East Africa for this project; the money was in fact largely provided by various groups in Central Africa. This sum is, of course, not adequate to finance a new university college. Indeed, the estimated capital expenditure for the College is $£ 2$ million (see Nature, 175, 181; 1955), of which $£ 1,250,000$ has been promised by the British Government from the Colonial Development and Welfare Fund.

\section{Announcements}

A symposrum on "Aluminium in Electrical Engineering" has been arranged by the Aluminium Development Association during May 16-17, to be held at the Institution of Electrical Engineers, Savoy Place, London, W.C.2. Inquiries should be addressed to the Aluminium Development Association, 33 Grosvenor Street, London, W.1.
AT the third annual general meeting of the Institution of Telecommunication Engineers, which is a professional body of radio, electronics and telecommunication engineers in India, Prof. $\mathrm{K}$. Sreenivasan was elected president, and the following were appointed officers of the Institution : Sri B. V. Baliga, Dr. Lal C. Verman, Sri D. D. Lakhanpal, Sri B. S. Rau, Sri S. S. Aiyar, Dr. Ram K. Vepa and Sri N. V. Gadadhar.

ThE spring meeting of the Institute of Metals, organized jointly with the Associazione Italiana di Metallurgia, the Société Suisse des Constructeurs de Machines and the Schweiz Verband für die Materialprufungen der Technik, will take place during April 29-May 4. All the scientific sessions will be held in London at Church House, Great Smith Street, S.W.1, except the May Lecture, which will be given in the Royal Institution, Albemarle Street, W.l. Details can be obtained from the Secretary, Institute of Metals, 17 Belgrave Square, London, S.W.1.

A Physical Society Conference on Physics of the Solid State, organized by Prof. L. F. Bates, will be held during April 8-10 in the Physics Department of the University of Nottingham. During the Conference, Prof. H. C. Urey, of the Enrico Fermi Institute for Nuclear Studies, University of Chicago, will deliver the Society's Guthrie Lecture at the University of Nottingham. The subject of his lecture will be "Some Chemical Limitations on Theories for the Origin of the Solar System". Inquiries should be addressed to the Physical Society, 1 Lowther Gardens, Prince Consort Road, London, S.W.7, marked for the attention of Miss Miles.

THE Anniversary Meetings of the Chemical Society will be held in the University of Cambridge during April 9-12. Prof. E. L. Hirst will deliver the presidential address on "Some Aspects of the Chemistry of the Fructosans" on April 11 at 11.15 a.m. in Lecture Room $A$, Examination Hall. Three symposia will be held during the period of the meetings. The sessions, which will run concurrently, will be devoted to: (organic) "Phosphoric Esters and Related Compounds"; (physical) "Reactions of Freo Radicals in the Gas Phase" ; and (inorganic) "Recent Aspects of the Inorganic Chemistry of Nitrogen". Further details can be obtained from the Chemical Society, Burlington House, London, W.1.

THE twelfth International Congress on Occupational Health has been convened by the Permanent International Committee on Industrial Medicine, founded in 1906 in Milan. Helsinki has been chosen as the place of the Congress, which will be held during July 1-6. The Congress has been planned so that subjects considered of general interest, including industrial noise, evaluation of invalidity, industrial hygiene and human engineering, will be discussed at plenary sessions during the mornings. Other subjects, judged to be of interest only to a limited number of members, will be dealt with at afternoon sessions. Registration forms (to be returned before April 1) and other informetion may be obtained from the Organizing Committee, Haartmaninkatu 1, Helsinki, Finland.

Erratum. In the communication entitled "Manganese Deficiency in Chlorella under Heterotrophic Carbon Nutrition" by Reisner and Thompson (Nature, December 29, p. 1473), Table 1, the dry weight of manganese-deficient material in line 3 is incorrect; for $7 \cdot 3$ read $4 \cdot 3$. 